\title{
THE LAY OF THE LAND: THE GEOGRAPHY OF TRADITIONAL CULTURAL EXPRESSION
}

\author{
Johanna Gibson
}

\begin{abstract}
"Through the use of ancestrally inherited designs, artists assert their identity, and their rights and responsibilities. They also define the relationships between individuals and groups, and affirm their connections to the land and the Dreaming". ${ }^{1}$

"You see, the land is not only to cultivate. The land is also for you to be cultivated in as a person. This is why, when the land is in the hands of others, you are only a tool".2
\end{abstract}

\section{Introduction}

The relationship between copyright and traditional cultural expressions (TCE) is an uneasy and problematic schema, one which not only locates the interests within the proprietary and objective character of copyright, but also one which shares much with the imperial narration of knowledge that accompanies histories of colonisation and global cartography. Intellectual property laws chart the modern trade routes built upon international knowledge economies. Knowledge is thus inextricably geographicallybound not only for traditional communities but also for the momentum of globalisation.

"The main battle in imperialism is over land, of course; but when it came to who owned the land, who had the right to settle and work on it, who kept it going, who won it back, and who now plans its future - these issues were reflected, contested, and even for a time decided in narrative". ${ }^{3}$

The narration of traditional cultural expression within the western social model for recognising and rewarding conventional forms of creativity - copyright - risks a similar colonising effect upon contemporary Indigenous and traditional cultural expression. That is, copyright models of dealing with traditional cultural expression potentially jeopardize the full repertoire of expression and language in the broader sense. Traditional cultural expression, in so far as it is inextricably linked to the land and to the language and coherence of a traditional group, emerges as the modern territorial dispute. Language and land are mutually and fundamentally constitutive:

"My rights to use this image arise by virtue of my membership of the land owning group. The right to use the image is one of the incidents arising out of

\footnotetext{
${ }_{1}^{1}$ Wally Caruana, Aboriginal Art, London: Thames and Hudson, 1993, at p. 15, as quoted in Terri Janke, Minding Culture: Case Studies on Intellectual Property and Traditional Cultural Expressions, Geneva: WIPO, 2003, at p. 75.

${ }^{2}$ T. Marcelino, a Guarani farmer from Bolivia, as quoted in UNICEF, Ensuring the Rights of Indigenous Children, Innocenti Digest 11, October 2003, at p. 2.

${ }^{3}$ Edward W. Said, Culture and Imperialism, London: Vintage, 1994, at p. xiii.
} 
land ownership. [...] Aboriginal art allows our relationship with the land to be encoded". ${ }^{4}$

Intellectual property may be of parallel interest, but arguably, it will never be the overriding and defining interest for traditional-knowledge holders. When copyright is useful for traditional cultural expression it is because there is an issue of copyright at stake, but there is no protection of traditional cultural expression as such. The protection is of intellectual property, not traditional knowledge.

The entry-point for this discussion must therefore include a consideration of the relationship between expression and the land, and the relationship between land and the constitution of community subjectivity. Given that, this collection is addressing the issues arising with the access to and use of traditional knowledge and TCE in a digital environment, in an almost paradoxical way, that obvious entry-point is land.

\section{The Knowledge Landscape}

It is critical, in considering the circulation and apportionment of TCE in a digital setting, to recognise that the crucial mechanism of transmission for Indigenous and traditional groups is that of tradition. In other words, tradition is not the subject matter of protection, reservation or rationing when examining the negotiation of traditional knowledge; rather, it is the mechanism by which information is transmitted and exchanged. Therefore, tradition is not the object or end in itself, it is a tool for transmitting knowledge in abstract ways similar to the functioning of intellectual property laws and indeed copyright. Copyright is the dominant mechanism by which to access the right to benefit from one's creative output. ${ }^{5}$ The question is not that of whether tradition as such may be the subject matter of a human right, but whether Indigenous and traditional groups will be able to realise the right to benefit in a culturally relevant and appropriate way if that mechanism of tradition is not sustained. Indeed, it is necessary to examine whether copyright and other areas of intellectual property law may at certain points interfere with that right for Indigenous and traditional groups.

Crucially, then, the fundamental concern when examining the relationship between TCE and copyright is the conflict between what are arguably two incompatible mechanisms for the transmission and exchange of information and knowledge - that of copyright and that of traditional systems of dissemination and exchange. In dealing with the protection of traditional cultural expression, it is thus necessary to examine the conflicts between two differing and at times opposing systems and the inescapable consequences for cultural diversity and cultural self-determination.

It is in this acknowledgement of tradition as a mechanism rather than an object of protection, that the relevance of land becomes much clearer. Just as copyright, as a mechanism, necessarily must rely upon the characterisation of an object (an expression) similarly traditional knowledge is articulated upon the tangibility of tradition, the recording process of tradition. Those recording processes, however disparate, generally converge upon the tangibility of the land. In this way, the land records the traditional process in belief systems and other aspects of traditional cultural expression otherwise seemingly "uncertain" for the purposes of copyright. In that, traditional relationships to knowledge and cultural expression, generally speaking, are articulated upon a relationship to the land, land ownership or guardianship is thus instrumental in

\footnotetext{
${ }^{4}$ Marika Banduk, an Indigenous Australian artist speaking about the painting "Djanda and the Sacred Water Hole", as quoted in Janke, supra note 1, at p. 11.

${ }^{5}$ Article 15(1)(c) of the International Covenant on Economic, Social and Cultural Rights (CESCR, concluded 16 December 1966, entered into force 3 January 1976).
} 
recognising interests and achieving relevant and effective protection of traditional cultural expression. That is, stewardship of the land gives rise to the right to knowledge. The use and dissemination of knowledge is characterised upon this relationship to the land.

"The image is associated with a place on Rirratjingu land called Yalangbara (which is at Port Bradshaw south of Yirrkala) and represents the events associated with the Djangkawu that took place there. My rights to use this image arise by virtue of my membership of the land owning group. The right to use the image is one of the incidents arising out of land ownership. [...] Aboriginal art allows our relationship with the land to be encoded, and whether the production of artworks is for sale or ceremony, it is an assertion of the rights that are held in the land. The place, Yalangbara, and the particular story of the Djangkawu associated with it do not exist in isolation. They are part of a complex or 'dreaming track' stretching from the sea off the east coast of Arnhem Land through Yalangbara, across the land to the west of Ramingining and Milingimbi". ${ }^{6}$

It is land, or territory, that is the anchor or absent in all of these concerns - intellectual property, traditional knowledge and cultural expression, and the digital environment. In other words, the anxiety or trouble for the digital environment, for intellectual property and for traditional knowledge is land or indeed territory. The trouble is perhaps introduced by the very distinct differences in those conceptualisations of territory.

First, as will be explained in this chapter, intellectual property models are circumscribed by the legal, economic and philosophical western traditions of land and land ownership. In particular, with the current momentum towards international harmonisation of the standards and indeed the administration and enforcement of intellectual property laws, local and "seigneurial" knowledge and property is overcome in favour of a globalised cartography articulated upon the territorial loci of nation-states. The internationalisation of intellectual property re-emphasises national borders and discredits the seating of knowledge within community. The "feudal" community is overcome by the territorial authorities that drive the operation of globalisation. Global systems, paradoxically, rely upon the very sovereignty of the nation-state:

"[T] he current phase of globalization consists at least partly of global systems evolving out of the capabilities that constituted territorial sovereign states and the interstate system. In other words, the territorial sovereign state, which its territorial fixity and exclusivity, represents a set of capabilities that eventually enable the formal or evolution of particular global systems". ${ }^{7}$

This is relevant not only in considering current intergovernmental discussions of traditional knowledge and cultural expression at the level of the World Intellectual Property Organization (WIPO) and the application of intellectual property law, but also in other areas of international law relevant to the articulation of Indigenous interests, which rely similarly upon national capacities to globalise obligations. One of the most significant examples in this regard is the Convention on Biological Diversity (CBD). The CBD is based on national sovereignty over natural resources and aims to provide for the equitable sharing of the benefits derived, thereby in turn re-invigorating national sovereignties with respect to biological and intellectual resources. At the same time, the

${ }^{6}$ Marika Banduk, as quoted in Janke, supra note 1, at p. 11.

${ }^{7}$ Saskia Sassen, Territory, Authority, Rights: From Medieval to Global Assemblages, Princeton: Princeton University Press, 2006, at p. 21. 
text recognises the traditional knowledge of Indigenous and local communities. ${ }^{8}$ Despite this recognition of community, which is sustained throughout the document, the CBD nevertheless emphasises the sovereignty of states with respect to the preservation of biological resources, noting that such protection is ultimately the responsibility of states. ${ }^{9}$

Secondly, the translation of traditional knowledge systems within intellectual property models imposes similarly competitive, rivalrous and crowdable notions upon the subject matter itself (not merely the system of protection). The very territorial nature of intellectual property rights maps clearly onto notions of national capacity and resources. Capacity and authority through knowledge is territorially tied to the sovereignty of the nation-state. Intellectual property becomes indexical of a contemporary territorial kingship ${ }^{10}$ in the nationalism of the knowledge economy. ${ }^{11}$ This continues despite the semantic shift to the idea of the dynamic creative economy ${ }^{12}$ (as distinct from the artefacts of the knowledge economy) and the business models that have developed upon advancing technological processes of exchange and dissemination - the digital environment.

Thirdly, in mapping traditional knowledge through intellectual property, traditional relationships to land (through the rendering of the knowledge embedded in that land) are similarly translated into competitive western systems. Importantly, this is significant not only from the perspective upon creativity and the creative process that is motivated by intellectual property frameworks, but also in terms of the repositioning of the governance structures upon traditional knowledge away from community models to national sovereignties and global interstate trade cartographies.

Fourthly, traditional and Indigenous communities have been subjected to the same rationalisation, whereby authenticity is realised and demonstrated through attachment to the land in a literal and possessory westernised sense, rather than in what is arguably a more relevant and meaningful sense. That is, that rationalisation is from the externalised

${ }^{8}$ Preamble to the Convention on Biological Diversity (CBD, adopted 5 June 1992 at the United Nations Conference on Environment and Development in Rio de Janeiro, entered into force 29 December 1993) and Article 8(j) CBD.

${ }^{9}$ Preamble to the CBD.

${ }^{10}$ The relationship of modern nationalism to divine authority is useful to respond to in this context. Saskia Sassen explains it drawing upon the historical developments of the French monarchy and the paradoxical invocation of popular sovereignty and nationalism. Sassen (supra note 7, at p. 19) writes: "A variety of conditions and decisions established France early as a distinct entity and stimulated a specifically French identity, which included loyalty and patriotism. These developments allowed the formation of an abstract notion of sovereignty, which eventually becomes popular sovereignty, even though divine kingship was precisely the specific capability the French Revolution aimed at destroying. The divinity of the French kings can be interpreted as feeding the mythical character of the nation in the later secular period. Nationalism and patriotism can then be seen as capabilities developed through territorial kingship and its claim to divine origins".

11 The term "knowledge economy" refers to the phenomenon where knowledge and knowledge-intensive activities are recognised as a significant input/output for societies and their economies. In other words, knowledge is itself an important resource and commodity of a society - an economic asset. This is understood in terms of the lessening significance of trade in basic tangible goods and the increased importance of knowledge and knowledge products as economic commodities in trade (see the Agreement on Trade-Related Aspects of Intellectual Property Rights [TRIPS], consolidated in the Agreement Establishing the World Trade Organization with Understanding on the Rules and Procedures Governing the Settlement of Disputes and Trade Policy Review Mechanism, Marrakesh, 15 April 1994, TS 57(1996) Cm 3277; (1994) 33 ILM 15, entered into force 1 January 1995). The term can be traced to economic commentaries of the 1960s with the increased economic significance of services over that of traditional industries (like manufacturing). See Peter F. Drucker, The Age of Discontinuity: Guidelines to Our Changing Society, New York: Harper and Row, 1969.

${ }^{12}$ Largely derived from the idea of the "creative industries", the term "creative economy" has gathered momentum in recent years, particularly at the level of government policy-makers, in its resonances with ongoing creativity and dynamic use. See Peter Coy, "The Creative Economy" BusinessWeek Online, 28 August 2000. See also the Creative Economy Programme, launched in late 2005 by the UK Government Department for Culture, Media and Sport (DCMS) and built upon policies of international competitiveness for the UK as a creative hub in an international knowledge or creative economy (http://www.cep.culture.gov.uk/). 
perspective rather than from within the community itself, in that it is concerned with the "nostalgic" construction of Indigenous and traditional interests. This construction is vested in the continuity of connection to place and geographic community which ultimately betrays a self-conscious western construction of cultural resources and knowledge. That is, such knowledge and the relationship to that knowledge is understood only within the context of the institution of western legal paradigms and the legitimated justice of individual property interests. The requirement for connection to place is at once already circumscribed within a discourse that "traditionalises" the Indigene and is a requirement itself defeated by the process of modernity (that is, how does one fulfil the requirement of place in an urbanised group?). Furthermore, within the economics of this attachment to place, the tradition of those not identifying with place is discredited.

Finally, when it comes to the digital environment, we see industries based upon intellectual property struggling to chart and define those territories by transforming knowledge into "land" as it were. The very title of this collection, the digital "environment", demonstrates the importance of territory in giving effect to the issues at stake.

\section{Intellectual Property and Land's End}

Much has been said about the relationship between intellectual property and personal property - an idea is not a book, but some argue that the business models built upon copyright and other areas of intellectual property law render an idea, a "book", as such. That is, the attachment of intellectual to property presupposes an externalisation of the idea as object, as unit. But what is particularly interesting is the way in which an idea is indeed similar to a "book" or in fact a "library". In other words, the way in which an idea is reterritorialised by intellectual property models is remarkable for rendering land ownership (at least in a conceptual sense, the "place" of the book) intriguingly relevant. This is especially significant in the context of traditional cultural expression.

Indeed, land itself has acquired a proprietary meaning in and of itself, having developed as a synonym for ownership and possession. The implicit trace of the relationship between individuals and land, between individuals and things, appears to dominate the background of all basic conceptualisations of proprietary relationships. Therefore, while ideas and intellectual property in the context of personal property have been considered at length throughout the literature, it becomes pertinent to investigate this important relationship to land. In this present discussion, this is particularly relevant in the context of the importance of land to the resilience and significance of traditional cultural expression and the dissemination of that expression within traditional communities.

What indeed may this landing of ideas, as it were, indicate for the economic geography created through knowledge and the accompanying property frameworks? And what might it say about the possessory cultural relations to knowledge - territory which today is much more regularly the subject matter of demarcation through legal disputes in the courts than is land. And yet the basis of understanding of proprietary models in the western world, and indeed the basis of western/European society and class systems, remains that of land ownership. In the modern knowledge economy, is this emphasis a distraction from the territories at stake?

Therefore, rather than looking at the expression of ideas as chattels (the usual way in which the proprietary nature of intellectual property is described and challenged), I would like to look at the way in which ideas and information relate to territories. How 
does information transform a site? For instance, information in an archaeological site, or the transformation of a site by the existence and recognition of architectural works, will have tangible economic and legal effects upon a site. In the former, arguably the value at stake is that established in antiquity and archaeotourism, where guidebooks, oral discussions and performances, and even the structure of tours ${ }^{13}$ may transform the site through some form of intellectual property protection. Importantly, each change is protected, transforming the land in multiple and overlapping ways. The information transforms the site; the value of the land inheres in the idea.

Similarly, traditional knowledge and cultural expression embedded in the land logically transforms a site. But how might that be realised beyond the mere architecture of copyright? What does intellectual property have to do with that information? The digital landscape provokes similar questions and conceptual concerns. How does knowledge realise an economic and social geography in the context of the Internet?

In this sense, of particular interest is the relationship between intellectual property frameworks and not goods (as personal property) but land (as real property). That is, as distinct from a relationship between people and things, a perspective instead upon the connections between knowledge and land indicates more clearly the relationships between people. And in this sense, the historical developments in the use of land and feudal societies are explicitly relevant and instructive. While today, the distinction between real property and personal property is critical to the common law of property, this distinction is clarified by the history of land use and contract (as somewhat distinct from the accumulation of chattels) as the basis for Anglo-Saxon society. Not only was land the economic basis of feudal society, but also land use explains a significant turning point in the conferral of status and as the source from which such chattels and resources (eventually as items of personal property) could be derived. Indeed, in Scottish law, statutory copyright was heritable property rather than movable until the $1840 \mathrm{~s},{ }^{14}$ thereby sustaining until relatively recently this relationship between people as distinct from the attachment to things.

Nevertheless, the ownership of land is not a natural right in the sense that it is a comparatively recent development in relationships to the land. In feudal societies, ownership was not necessarily a relevant nor was it a reasonable explanation of the relations at stake. Where the term does emerge in the late $15^{\text {th }}$ century, it is to denote not legal title but rather the relationship to the land as beneficiary that is established through dynamic, living use. ${ }^{15}$ This critical nature of "use" is fundamentally instructive to present discussions of copyright and intellectual property laws, and the nature of the "value" to be found in knowledge. Indeed, it is not as object of access (the unit) but as use. Similarly, this historical development of the term supports arguments for use as a crucial value in the maintenance of intellectual property. At this juncture, the location of value shares much with the mechanism of tradition recorded in the land. Use is not wastage of cultural artefact but indeed a question of the right to benefit in relevant ways from that cultural output.

In feudal systems, while the King owned the land, neither the lord nor the vassal tenant owned land absolutely. Rather, the land was held by the tenant on behalf of the

\footnotetext{
${ }^{13}$ In some jurisdictions (such as France), the structure of the tour may be subject to protection through the recognition of format rights.

${ }^{14}$ George J. Bell, Principles of Mercantile Jurisprudence, $4^{\text {th }}$ ed., Edinburgh: Edinburgh University Press, 1821 , at p. 68. Copyright was deemed personal property by the Copyright Act 1842, Section 25.

${ }^{15} \mathrm{John} \mathrm{H}$. Baker suggests that one of the earliest examples of the use of "ownership" as a legal relationship is in B \& M 103 (c 1490). But in fact, there, "le owner" was used to denote a person without legal title. In other words, and what is most important for the present discussion, le owner was a beneficiary through use. See John H. Baker, An Introduction to English Legal History, $4^{\text {th }}$ ed., London: Butterworths, 2002, at p. 223.
} 
lord. This dynamic "use" relationship was inevitably ossified as the law of tenures in the $15^{\text {th }}$ Century. Nevertheless, it is significant that the relationship to land in English legal history was borne of a social fact rather than an immutable legal concept. In other words, land value originates in the relations between people and the land's use, as distinct from control and exclusive ownership of the land. An understanding and appreciation of this relationship to use is relevant to the issues raised by contemporary legal interpretations of, and indeed public objections to, native title and land rights as turning on rights to exclude as distinct from parallel and cooperative use. The theory of rent is "a payment made to landlords for the right to use land and its appurtenances (the resources embedded within it, the buildings placed upon it and so on)" ${ }^{16}$ In other words, the property model, as it were, takes account of the way in which the resources, and indeed the information, embedded within the land transform the value of the land, and in fact the site itself. What Harvey identifies in this relationship is that land "evidently has both use value and exchange value". ${ }^{17}$

Rather intriguingly, however, within an intellectual property model of knowledge, what is the "use" of that knowledge? In that intellectual property laws have charted the

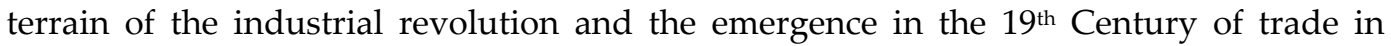
invention and other intellectual goods (as exemplified at the Great Exhibition and other international events of the period), ${ }^{18}$ developments in intellectual property laws have also charted the transformation of the key social and economic relations from those between people to those between individuals and things. Thus, the change is that from dynamic means (use value) to the objects as ends (exchange value). The "use value" is not only deferred by the exchange value of knowledge (in a model of trade in intellectual property) but also made increasingly difficult to realise, if we accept the positions of many civil society and consumer organisations which argue that intellectual property protection and laws operate as a genuine obstacle to access and thus to the achievement of use. ${ }^{19}$ And indeed, this is relevant when examining dealings with knowledge as cultural relations, in that there is arguably a loss or diminishing of the cultural and social dimension within a strictly economic model of the creative economy.

\section{Knowledge, No Use for a Person}

${ }^{16}$ David Harvey, Limits to Capital, new ed., London: Verso, 2006, at p. 330.

${ }^{17}$ Ibid.

${ }^{18}$ Attention to intellectual property as export and its vulnerability in international demonstrations, such as the international trade fairs of the period, were directly motivating factors behind the establishment of the Paris Convention for the Protection of Industrial Property of 20 March 1883, and the Berne Convention for the Protection of Literary and Artistic Works of 9 September 1886.

${ }^{19}$ The international "Access to Knowledge" movement is a cooperation between a number of civil society organisations towards the conclusion of an international treaty on access to knowledge to be presented to the WIPO General Assembly. The movement gained its momentum at an international meeting of civil society organisations, academics and governments in Geneva in September 2004, "The Future of WIPO." At this meeting Argentina and Brazil tabled a document calling for WIPO to fulfil its mandate with respect to developing countries (the "Development Agenda") and meeting participants drafted the Geneva Declaration on the Future of the World Intellectual Property Organization (2004), calling for a Treaty on Access to Knowledge and Technology. The full text of the Declaration, together with signatures, is available at http://www.cptech.org/ip/wipo/genevadeclaration.html. The proposal by Argentina and Brazil, for the establishment of a development agenda for WIPO, was tabled at the $31^{\text {st }}\left(15^{\text {th }}\right.$ Extraordinary) Session of the General Assembly of WIPO, 27 September-5 October 2004 (WO/GA/31/11; WO/GA/31/12; WO/GA/31/13). 
"Knowledge is and will be produced in order to be sold, it is and will be consumed in order to be valorized in a new production: in both cases, the goal is exchange. Knowledge ceases to be an end in itself, it loses its 'use-value'", ${ }^{20}$

Jean-Francois Lyotard speaks of the "mercantilization of knowledge", ${ }^{21}$ whereby the economic exchange of information commodities becomes the governing organising principle of society and the governance that might be achieved with respect to any entity, whether it be the nation-state or the traditional community, is compromised and rendered secondary to the governance of the market. Lyotard asks, when it comes to information, "will the State simply be one user among others?" 22 One may also ask, when it comes to traditional knowledge, does the assimilation of customary management of that knowledge within intellectual property render the community a mere user of its own knowledge?

For this question, it is prudent to consider the relationship between intellectual property protection of TCE and the access of traditional communities. That is, how might the commoditisation of TCE through copyright protection interfere with the genuine access of communities to their own knowledge? This question must be considered not only in terms of the creation of possible restrictions on use in an intellectual property sense, but also through the destruction of value and the creation of offence in the use of the expression in question. In other words, access may be compromised such that in a real and relevant way the value of that knowledge to the Indigenous and traditional community is no longer available.

It is arguable that the "branding" of value through the intellectual property system indeed necessarily transforms a community's role and responsibility with respect to its knowledge in this way. In rendering "value" through this kind of model, the "loss" of knowledge suddenly has a commercial and tangible effect. And the "blame" for that loss of knowledge, now re-made as personal property, is constructed as resting with the "identity" of the Indigenous and traditional group, the "personality" as it were:23 "the failures of public sympathy, state institutions, and lawful forms of property become the failures of local people to maintain their 'culture'". ${ }^{24}$

We see these emphases on preservation in disputes regarding the repatriation to traditional communities of human remains held in museums. Recently in the United Kingdom, the Natural History Museum settled a claim brought by the Tasmanian Aboriginal Centre through the Australian High Commission. The claim challenged the museum's use of the remains for anthropological research and tests, demanding return of the remains for customary burial; however, the museum countered that the specimens would be returned following completion of the testing, arguing in favour of the significance for international anthropological and scientific research and the potential loss to the research community if such experimentation were to be stopped. The claim was finally settled in May 2007 after three days of mediation.

Similarly, the uniqueness of traditional cultural expression is at times deployed as the basis for preservation ex situ through museums and anthropological archives. According

${ }^{20}$ Jean-François Lyotard, The Postmodern Condition: A Report on Knowledge, Minneapolis: University of Minnesota Press, 1984, at pp. 4-5.

${ }^{21}$ Ibid. at p. 5.

${ }^{22} \mathrm{Ibid}$. at p. 6 . This becomes relevant again in Chapter 5 where the discussion of freedom suggests the covert regulation of that freedom not only through expanded intellectual property rights but also through the market (as in media monopolies and so forth).

${ }^{23}$ See the discussion of identity and ownership in Johanna Gibson, Community Resources: Intellectual Property, International Trade and Protection of Traditional Knowledge, Aldershot: Ashgate, 2005, at Chapter 1.

${ }^{24}$ Elizabeth A. Povinelli, The Cunning of Recognition: Indigenous Alterities and the Making of Australian Multiculturalism, Durham: Duke University Press, 2002, at p. 189. 
to the narratives within which it is authenticated, if traditional knowledge (particularly ancient knowledge) is used by community it is almost a waste. ${ }^{25}$ In other words, traditional "use" is compromising the "value" that is otherwise consolidated by reading that knowledge and consumption through intellectual property frameworks. According to this modelling, traditional knowledge has no "use-value" other than that precipitated by these laws and usually only as ancient heritage or "history". The value of that knowledge, within western legal and cultural frameworks, is ascertained through constructions of its authenticity, its collectability, its objectification and commodification: And this construction arguably is effected by intellectual property perspectives.

\section{The Culture Plot}

Traditional use in such cases is presented therefore as "waste". In contrast, preservation is presented by proponents of the institutional model as a priority that is achievable only in this way, which arguably depends very much upon the commodification of knowledge as a fixed and legitimate object of "Culture". Thus, this commodified and ossified state of knowledge is favoured over a performative and generative value with particular cultural effects for communities: "'culture' appears to denote a form of property". ${ }^{26}$

However, if we return to the opening example, it is clear that not only in the intrinsic link between the traditional cultural expression and the land, but also in the performance of that traditional cultural expression and the relationship to the land, an important distinction in the "proprietary" relationship emerges. That is, traditional custodianship models can perhaps be understood as operating upon the interaction between members of the community themselves, rather than between individuals and things, as in conventional proprietary relationships.

Territory emerges, therefore, in these cultural interactions and the exchanges of knowledge, as it were. Land is therefore a resource of the community that is recognised through the tradition and cultural knowledge inhering in the land, rather than competitive relationships to land: "it is land involved in a particular relationship which is perceived as a resource, and thus the land itself refers to the site of real valuation generative or productive relations between persons". ${ }^{27}$ The site of contestation, of territory, is that of culture and community. "Land" is always already marked by community, the marking and making of territory, but physical land in and of itself is indexical of the depth of community integrity indicated by that land.

Therefore, while communities may be dispersed and alienated from their physical land (place), the assertion as communities cannot be defeated by this displacement, because of this disembodied memory of the community subjectivity (space). ${ }^{28}$ This relationship anatomises territory. In other words, territory cannot be realised and

${ }^{25}$ See Moira G. Simpson, Making Representations: Museums in the Post-Colonial Era, London: Routledge, 2001, at pp.198-199. Simpson discusses the way in which repatriation is almost presented as a threat to preservation of that knowledge.

${ }^{26}$ Miguel Tamen, Friends of Interpretable Objects, Cambridge, MA: Harvard University Press, 2001, at p. 73.

${ }^{27}$ James Leach, "Land, Trees and History: Disputes Involving Boundaries and Identities in the Context of Development" in Lawrence Kalinoe and James Leach (eds.), Rationales of Ownership: Transactions and Claims to Ownership in Contemporary Papua New Guinea, Wantage: Sean Kingston Publishing, 2004, pp. 42-56, at p. 42.

${ }^{28}$ Félix Guattari refers to the impossibility of being wiped out in the process of "historical discursivity", such as the discursive translation of traditional knowledge through intellectual property law and through its misappropriation into non-traditional copyright, inventions, and so on, because of the persistence of the irreversible refrain of "the incorporeal memory of collective subjectivity". See Félix Guattari, Chaosmosis: An Ethico-Aesthetic Paradigm, Sydney: Power Publications, 1995, at p. 27. 
accessed without the facilitation of community management and governance and that is necessarily through the recognition of customary law.

It is in this sense that the marking and recognition of territory, of "land", therefore, occurs not through imperial models of "title", but through community: "All the inhabitants have to do is recognize themselves in it when the occasion arises". ${ }^{29}$ Thus, territory is not de-limited by western conceptions of physical space, of utility, and of resources. Deleuze and Guattari have suggested that "[w]hat defines the territory is the emergence of matters of expression (qualities)". ${ }^{30}$ So, what defines the territory is "community".

"The territory is not primary in relation to the qualitative mark; it is the mark

that makes the territory". ${ }^{31}$

Thus, the relationship of community to territory and resources is realised not through the linkage of territory as object with an individual legal subject, but in its sense-making through customary law, which will differentiate territory (understood not just as land, but as knowledge, culture, and so on) according to subjects who are recognised by the community and perform within the community. In other words, rights will be conferred upon subjects because of their status within the community, and not despite it. Those individuals will not be "subjects", as such, unless recognised by the community. The agency of community does not constitute the individual subject, but the territory (knowledge, culture, land).

\section{Intellectual Property, Cultural Cartography}

The assimilation of traditional knowledge within intellectual property models suggests, therefore, a threat to this connection between people through the land by the very nature of its attention to the relations between individuals and things. This transformation from the efficacy of traditional affinities to that of intimacy between people and things is at once a transformation in the mechanism of tradition in the transmission and exchange of knowledge, compromising traditional mechanisms of preservation and management on a cohesive local basis. However, as the dominant language by which the international trading community captures value in culture and in the creative, intellectual property is also the international forum in which this discussion is set to be resolved.

These questions are formally under the administration of the Intergovernmental Committee on Intellectual Property and Genetic Resources, Traditional Knowledge and Folklore (IGC) ${ }^{32}$ of the World Intellectual Property Organization's (WIPO). ${ }^{33}$ The IGC is specifically assigned the task of examining and resolving applications of intellectual property to questions of access to and protection of traditional knowledge and traditional

\footnotetext{
${ }^{29}$ Marc Augé, Non-Places: Introduction to an Anthropology of Supermodernity, London: Verso, 1995, at p. 44.

${ }^{30}$ Gilles Deleuze and Félix Guattari, A Thousand Plateaus: Capitalism and Schizophrenia, Minneapolis: University of Minnesota Press, 1987, at p. 315.

${ }^{31}$ Ibid.

32 The WIPO Intergovernmental Committee on Intellectual Property and Genetic Resources, Traditional Knowledge and Folklore (IGC) was established in the $26^{\text {th }}$ (12 ${ }^{\text {th }}$ Extraordinary Session) of the WIPO General Assembly, held in Geneva, 25 September to 3 October 2000 to consider and advise on appropriate actions concerning the economic and cultural significance of tradition-based creations, and the issues of conservation, management, sustainable use, and sharing of the benefits from the use of genetic resources and traditional knowledge, as well as the enforcement of rights to traditional knowledge and folklore. See WIPO, Matters Concerning Intellectual Property, Genetic Resources, Traditional Knowledge and Folklore, WO/GA/26/6, 25 August 2000. See also Wend Wendland's contribution to this volume.

${ }_{33}$ WIPO was established in 1967 with the task of the administration of intellectual property treaties and conventions signed by member nations.
} 
cultural expression. This discussion takes place in the context of international instruments, national laws of member states, and current debate over balancing interests between commercialising traditional knowledge, on the one hand, and protecting it against commercialisation, on the other. Looking at the work of WIPO and the guidelines and principles produced by the IGC there is indeed, at the intergovernmental level, an important re-location of the use value of traditional knowledge within communities in the acknowledgement of the importance of customary law not only for relevant management, but also for effective management in a commercial sense. As set out in the WIPO Revised Provisions, ${ }^{34}$ customary practices are a central articulation for the relevant development of protection mechanisms:

\section{Objectives}

Support customary practices and community cooperation

(vi) respect the continuing customary use, development, exchange and transmission of traditional cultural expressions/expressions of folklore by, within and between communities;

Further, as the general guiding principles make clear, relevant protection should not make it at the same time impossible for communities to continue traditional and customary forms of developing and disseminating knowledge:

\section{General Guiding Principles}

(h) Principle of respect for customary use and transmission of traditional knowledge

Protection should not hamper the use, development, exchange, tansmission and dissemination of TCEs/EoF by the communities concerned in accordance with their customary laws and practices. No contemporary use of a TCE/EoF within the community which has developed and maintained it should be regarded as distorting if the community identifies itself with that use of the expression and any modification entailed by that use. Customary use, practices and norms should guide the legal protection of TCEs/EoF as far as possible.

For the customary law of communities, the value of resources and their necessary protection is derived from systemic community practices and the preservation of connections not simply with place but with habit and the past (the space ${ }^{35}$ of community). The essential problem for the organised protection of traditional cultural expression in the context of community use, and the maintenance of the use-value for those communities, is to reconcile these principles with the risk and individualisation attached to modern notions of property, development and trade efficiency. ${ }^{36}$

The progress of society, and ultimately the observations of "development" levelled at traditional communities are subject to the self-conscious and reflexive nature of modernisation and development and thus, the relationship between the process of modernisation and the institutions of that development, particularly that of the legal

34 These draft provisions have been annexed to documents WIPO/GRTKF/IC/8/4, 8 April 2005, WIPO/GRTKF/IC/9/4, 9 January 2006, WIPO/GRTKF/IC/10/4, 2 October 2006, and WIPO/GRTKF/IC/11/4(c), 26 April 2007, considered by the WIPO Intergovernmental Committee on Intellectual Property and Genetic Resources and Folklore at its Eighth, Ninth, Tenth and Eleventh Sessions. They are reproduced in their entirety at the end of the volume in Annex 1.

${ }^{35} \mathrm{~A}$ more detailed consideration of the relationship between place and space, introduced here, is given in Gibson, supra note 23, at Chapter 7. See also Michel de Certeau, The Practice of Everyday Life, Berkeley: University of California Press, 1988.

${ }^{36}$ See Jean-François Lyotard's discussion of the concept of development in Jean-François Lyotard, The Inhuman, Stanford: Stanford University Press, 1991, in particular at pp. 2-7. 
institution. ${ }^{37}$ As discussed earlier, the rendering of indignity through the attachment to land creates a proprietary or possessory notion of authenticity, of community and of personhood through that attachment to place. This attachment to place must be problematised as a strategy of categorisation which continues to archive and historicise the traditional and Indigenous community, without accounting for its capacity for evolution in a contemporary context:

"Our increasing interconnectedness - and our growing awareness of it - have not, then, made us into denizens of a single village. Our most basic social identities - the identities that are called 'tribal' in Africa, for example, or the ethnic groups of the Balkans or the modern multicultural city - are no longer village identities. Everyone knows you cannot have face-to-face relations with six billion people. But you cannot have face-to-face relations with a hundred thousand or a million or ten million (with your fellow Serbs or Swahilis or Swedes) either; and we humans have had practice in identifying, in twos, cities, and nations, with groups on this grander scale". ${ }^{38}$

Departing from models fixing community to place, community resists determination and placement, but rather experiences "locality" through the practice and interaction of culture. Arguably the same "demonstration" and experience of locality could be recognised in the digital environment, where the interactions between participants describe the geography of the Internet (through hubs and nodes, and the increasing relevance of networks as a model for understanding the way in which information is used and indeed an economic geography is maintained).

This locality is indeed realised in the documents emerging from the WIPO IGC in that this connection between land and knowledge is available in the acknowledgement of customary laws. As distinct from place, the space (or site of contestation) of traditional resources, is that of culture - knowledge is land. A reduction to place alone, leads to a misappropriation and objectification of traditional knowledge that is inevitably disenfranchising and displacing to Indigenous and traditional groups. ${ }^{39}$ Access to selfgovernance of traditional knowledge according to customary law, therefore, is necessary for cultural autonomy and thus gives place to the disenfranchised (by the law) and displaced (from culture):

"Culture is the battlefield of a new colonialism; it is the colonized of the twentieth century. Contemporary technocracies install whole empires on it, in the same way that European nations occupied disarmed continents in the nineteenth century. Corporate trusts rationalize and turn the manufacture of signifiers into a profitable enterprise. They fill the immense, disarmed, and almost somnolent space of culture with their commodities [...]. This economic system [...] [replaces] the act of democratic representation with the reception of standardized signifiers that destine workers to become consumers, and that turn people into a public mass [...]. [C]ulture appears as the field of a multiform battle between the forces of the soft and the hard. It is the outrageous, cancerous

${ }^{37}$ Ulrich Beck, Anthony Giddens and Scott Lash, Reflexive Modernisation: Politics, Tradition and Aesthetics in the Modern Social Order, Cambridge, MA: Polity Press, 1994.

${ }^{38} \mathrm{~K}$. Anthony Appiah, "Citizens of the World" in Matthew J. Gibney (ed.), Globalizing Rights, Oxford: Oxford University Press, 2003, pp. 189-232, at p. 195-196.

${ }^{39}$ It is important to assert that this is not to deny the importance of physical land, but to reject the simplification of Indigenous cultural origins to western conceptions of real property and competition for resources. Thus, it opens up the space of community, rather than confines it to place. 
symptom of a society divided between the technocratization of economic progress and the folklorization of civic expression". ${ }^{40}$

If traditional knowledge is translated into information commodities for consumption, then all cultural obligations become assimilated within a relationship of consumption, with all communities transformed into consumers.

Arguably, the translation of these concerns within intellectual property frameworks decimates the relationship between community and resources that is necessarily indicative of "cultural knowledge", as distinct from commercial information to be traded by virtue of intellectual property "physicalisation" of that information. Indeed, resistance to the recognition of customary law and to sui generis protection for traditional knowledge relies upon an artificial polarisation of information/knowledge, high culture/tradition, art/folklore, invention/imitation, legal certainty/custom, and so on. This is continued not only in the rendition of traditional knowledge as open, shared, and for the benefit of all, but also in the charges of hypocrisy laid against Indigenous and traditional groups wishing to commercialise or to license their traditional knowledge where appropriate. ${ }^{41}$ However, importantly the WIPO Revised Provisions ${ }^{42}$ acknowledge this by emphasising the continuation of traditional mechanisms for dissemination, transmission and exchange - that is, tradition as the necessary mechanism or circumstances for traditional knowledge and cultural expression. This is apparent not only in the objectives (particularly paragraph (vi)) and in the general guiding principles (paragraph (h)) but also in the substantive provisions. Article 5(a) provides:

\section{(a) Measures for the protection of TCEs/EoF should:}

(i) not restrict or hinder the normal use, transmission, exchange and development of

TCEs/EoF within the traditional and customary context by members of the relevant community as determined by customary laws and practices;.

The recognition of customary law will, therefore, actualise the necessary process of belonging that may be fractured through ongoing colonisation by western legal models and "impersonation" through the appropriation and re-presentation of traditional knowledge and traditional cultural expression.

Thus, the practice of culture "creates" locality or space, as it were, in a kind of countering of the effects of globalisation. ${ }^{43}$ The homogenisation of culture through colonising effects, to an extent, is countered by the participation of community in the political, economic, social, and cultural public sphere. Mis-appropriation of traditional knowledge and expressions of culture is in itself a threat to that participation in that it is an effective loss of voice, a loss of the capacity "to express their world conception through systems of values and ethical standards". ${ }^{44}$ Mis-use of those systems compromises their meaning, exhausts their value, and transforms them into meaningless commodities. Thus, mis-appropriation is a literal appropriation of voice in that it is a

\footnotetext{
${ }^{40}$ Michel de Certeau, Culture in the Plural, Minneapolis: University of Minnesota Press, 1994, at p. 134.

${ }^{41}$ On knowledge development, see the discussion in Pat Howard, "The Confrontation of Modern and Traditional Knowledge Systems in Development" (1994) Canadian Journal of Communication 19:2.

${ }^{42}$ WIPO Intergovernmental Committee on Intellectual Property and Genetic Resources, Traditional Knowledge and Folklore. Revised Provisions for the Protection of Traditional Cultural Expressions/Expressions of Folklore: Policy Objectives and Core Principles.

${ }^{43}$ Indeed, this is the kind of environment that arguably is sought to be promoted by the United Nations Educational Scientific and Cultural Organization (UNESCO) Convention on the Protection and Promotion of the Diversity of Cultural Expression (adopted 20 October 2005, entered into force 18 March 2007) - that is, the capacity to practise culture.

${ }^{44}$ Para. 2 of the Istanbul Declaration on Intangible Cultural Heritage (adopted at the $3^{\text {rd }}$ Round Table of Ministers of Culture "Intangible Cultural Heritage, Mirror of Cultural Diversity” in Istanbul, 16-17 September 2002).
} 
transformation and obstruction of the means of expression. In offensive misappropriation of traditional cultural expression, there is a severance of the mechanism of connection between people, thereby potentially denying access to the political sphere, and ultimately denying the freedom of expression of Indigenous and traditional groups. Communities must be enabled to continue self-governance of resources according to customary law in order to participate in an international environment, without being assimilated or simplified as "individual", uniform legal subjects within existing systems. ${ }^{45}$

In the context of the ongoing WIPO discussions, ${ }^{46}$ it seems critical to maintain emphasis on the mechanism of tradition, and to re-assess the historical and jurisprudential basis for personal property and the departure from real property in this context. Indeed, the historical development of proprietary relationships to land provides insight not only into the limitations and assumptions of intellectual property, but also into the justifications for the protection of traditional cultural expression. Such justifications are based upon the very heart of the matter, as it were, the land.

\section{Conclusion}

So at this final point what is very significant in the work coming out of WIPO in particular is the way in which traditional knowledge is being mainstreamed, not as a form assimilated within intellectual property laws, but rather transforming intellectual property laws. Part of this is arguably a transformation in the relationship to knowledge not only for the purposes of the protection of traditional cultural expression but also in debates surrounding the value chains in intellectual property law, and the increasing attention to use and to the user in the creation, transmission and capture of value. In a digital environment and a creative economy increasingly confronted by user-generated content and viral markets, knowledge kinships are suddenly relevant. Capturing this attention, that communication of networks between people for which objects comprising intellectual property are merely indexical, is the real challenge for contemporary business models. Paradoxically, in a virtual environment, territory as the means of recording connections between people has become far more significant in a business context for which units are without currency. As Rosemary Coombe said to me once, "[i]ndigenous people have brought a great deal of creativity into intellectual property law". In the translation of tradition as a social fact into a legal concept, it is hoped that creativity will drive an effective international response.

\footnotetext{
${ }^{45}$ The notion of "belonging" and its attachment to place, through the translation of community and information in intellectual property law, together with the importance of "territory" in biodiversity, land rights, and human rights frameworks re-inscribe the central quality of the land in traditional cultural expression. In doing so, the concept of "territory" is significant in the realisation of the interpersonal and intra-communal relationship, and its situation within culture rather than geo-physical place. For further discussion, see Gibson, supra note 23.

${ }^{46}$ The mandate of the IGC was considered at the recent $43^{\text {rd }}$ Assemblies of the Member States of WIPO, 24 September to 3 October 2007. and renewal of its mandate approved by the $34^{\text {th }}$ WIPO General Assembly (Report of the $34^{\text {th }}$ WIPO General Assembly, WO/GA/34/16, para. 293). For a detailed discussion, see Wend Wendland's contribution to this volume.
} 